courer, B. C., was the first to introduce it into the Dominion. The septic-tank system has been in operation in Vancouver for six months and is giving the very best satisfaction. The neighboring city of Victoria is also installing it, and Seattle. Wash., is observing its operations closely with the view of adopting it in the near future, if in further time its success is fully demonstrative, which 1 thing is certain. So many inquiries bave been made at the City Hall here about the workings of it that our city engineer, Col. 'T. H. Tracy, has not time to answer then all, and has publisherl the following pamphlet on the subject:

TIL SEPTIC TANK

The economical disposal of sewage is a problem which has engaged the attention of engineers and scientists for a great many years with varying results.

Sand filtration, sewage farming, chemical precipitation, bacteria filtration are the most notable processes tried and found wanting. The objection to each of these processes are briefy as follows:

Sand Filtration, continuous or intermittent.-The area of suitable sand ground reguired is usually difficult to obtain in the neighborhood of a city, and if obtainable the elevation or position is such as to necessitate pumping and consequent continuous expense.

sewage Farming is growing into disuse for principally the same reasons.

Chemical Precipitation is expensive, both on account of the cos of the chemicals and handing and also the dealing witin the "sludge" which is produced in excessive quantity. The effluent is also liable to become offensive.

Bacterial Filtration.-Considerable success has attended thi method of treating sewage, but taken alone there are objections to it. In treating raw sewage the filters become clogged and require to be of considerable size and consequently expensive construction.

Septic Tanies.- The most effective method of treatment of sewage so far known is the Septic Tank, either used alone where the discharge is into salt water or where a high degree of purification not necessary or in conjunction with bacterial filters where the effluent must be comparatively pure. The tanks are usually con structed of concrete, arched over and of a capacity equal to 1 to 24 hours' flow of sewage with a depth of about 5 feet, the inlet and outlet pipes being turned down to a depth of about 18 feet below the surface, so as to leave the scum, which forms on the surface, and in which the bacterial action is carried on, undisturbed. After the tank has been in use about a week a brown scum forms on the surface, which gradually increases, until the full action is attained. In this scum the action of what are known as anaerobi bacteria goes on the greater part of the sewage being liquefied and a very small deposit resembling black aslies being deposited that about 90 per cent of the organic mitter in suspension and about 30 per cent of that in solution are removed and that the deposit does not require to be removed for several years. The practical result undoubtedly is that the offensive matter of the sewage is destrozed and the efliuent is sufficiently clear for discharging into salt water or where a high degree of purification is not necessary

Where discharged into a running stream or where greater purification is desirable a small bacterial filter or set of filters may be added in such a case much smaller area of fiter than if filters alone are used, as the effluent from the septic tan will go through at least four times as fast as the raw sewage, an the filter beds are not liable to be clogged.

The Vancouver Septic Tanks are three in number, designed for populations of 5000,3000 and 2000 , respectively, and were constructed in 1900 from plans furnished by the Septic Tank Syndicate, the first being put in operation about Jan. 1, 1901, and the others a month or two later. The results so far (August) ar quite satisfactory, though the quantity of sewage passing through is not such as to make the conditions most favorable for the devel opment of bacterial action. In one of the tanks near the Crematory the scavengers have been dumping night soil to the extent of five or six loads a night, and, though the last tank to be put in five or six loads a night, and, though

There have been no analyses yet made, either of the sewage or the effuent, but the practical effect of the bacterial action is very apparent. There is no smell from the tanks or the effuent. The earth has been filled over the tanks, leveled and seeded. so that the appearance of the surface is not unsightly or offensive in any way.

Some slight changes have been made in the plans furnished by the Syndicate: in order to avoid the use of wood covering for the the Syndicate : in order to avoid the use of wood covering for the tinued up and arched over, leaving only the necessary manholes appearing on the surface.

The above is a report 1 obtained to-day from our city engi. neer. Yours respectfully, W. J. MCGuigan, M.D.

\section{Value of Rest in Pulmonary Tuberculosis.}

Colorado Springs, Colo., Sept. 13, 1901.

To the Editor:--A very interesting letter from Dr. Chas. Denison appears in the columns of THE Joursar, of August 31.

It seems to me, however, that he, as well as many others Who speak of the treatment of pulmonary tubereulosis, voices "deeply-rooted error when he says in the concluding paracraph of his letter "they are all coming around to the same belief outdoor life in that climate where it can be had the easiest and most comfortably."

Having myself been the victim of pulmonary tuberculosis for more than seven years past and becoming thereby deeply interested in all that pertains to the therapeutics of this disease and watchful of all procedures for its amelioration in others as well, I feel that the subject of exercise in this con dition ought to be settled without much difficulty. In no other form of tuberculosis is an active functionating of the part affected permissible. In tuberculosis of hip, knee, spine or any other joint, rest is of prime importance. In glandular tuberculosis anything like massage is contra-indicated, and wio would be daring enough to advocate systematic thinking as a therapeutic measure in tubercular meningitis?

If once a clear conception of the difference necessary in outlining treatment for those predisposed to tuberculosis and those who already have it actively present is grasped, I believ' the present haziness on the subject of exercise will disappear.

As a prophylactic measure in those who by reason of inheritance, environment or poor anatomic development are predisposed to pulmonary tuberculosis, exercise of the chest and lungs is of undoubted advantage. When, however, an active process is present in the lungs the quieter such organs can be kept the better.

Soft, weak muscles are made firmer and stronger by systematic exercise. If such muscles become the seat of an in flammatory action no sane physician would prescribe exereise in any form for them.

I fail to see why the analogy is not fairly applicable to the lungs. If the lungs are sluggish, the pulmonary breath sounds are feeble, especially if the chest is contracted and the family history for pulmonary troubles is bad, by all means prescribe graded and systematic pulmonary gymnastics; but, on the other hand, when tuberculosis las already started in the lungs let us follow the rational methods used for treating tuberculosis elsewhere, by putting the lungs as nearly at rest as possible. I am well aware that not infrequently but one lung is affected, and when this is the case pulmonary gymnastics, while benefiting and strengthening the healthy lung, damages the one that is diseased, and occasionally the benefit is greater than the harm. I am, however, strongly of the opinion that generally in such cases the evil exceeds the good.

Full diet, fresh air, day and night, careful attention to the hygiene of skin and bowels, and rest, including a large amount of sleep (ten hours or more), with occasional counter-irritation to chest and otherwise symptomatic treatment when called for, sums up, it seems to me, what may be termed a safe basis for the treatment of pulmonary tuberculosis.

I may add that these are not merely theoretical considerations but are the results of observations on many afflicted, myself included. Truly yours,

W. F. Martin, M.D.

\section{A Use for Criminals.}

Palmerston, Ontario, Sept. 20, 1901

To the Editor:-President Mckinley has been laid to rest and his assassin remains to be dealt with by the law as a nuisance to society. Before he is exccuted might he not be used for some useful purpose? Recent investigations in tuberculosis and cancer, two of the world's greatest scourges, have shown the necessity of the use of a human subject for further research. Already a physician has offered himself as a subject to test whether bovine tuberculosis is transmissible to man. The necessary experiments would not entail any great. suffering on the criminal, and public opinion generally would be thoroughly in accord. I can see no objection to this use of desperate criminals. This practice was in vogue when Jenner introduced vaceination to the world, but in the nineteenth century seems to have fallen entirely into disuse. W. R.

\section{Nerve Nostrums and Their Dangers.}

Son Yea, N. Y., Sept. 21, 1901.

To the Editor:-The undersigned is preparing a paper on "Norre Nostrums and Their Dangers," by request of Dr. 